\title{
- Sorovares de Salmonella isolados de materiais avícolas no período de 1994 a 1999
}

\section{- Salmonella serovars isolated from poultry material from 1994 to 1999}

*Faculdade de Medicina Veterinária e Zootecnia - UNESP

Departamento de Clínica Veterinária Serviço de Ornitopatologia Caixa postal 560 CEP: $18618-000$ - Botucatu - SP End. Eletrôn.: andreatti@fmvz.unesp.br

* Raphael Lúcio Andreatti Filho ${ }^{1}$ - CRMV-SP - n ${ }^{\circ 4189}$

Sueli Aparecida Fernandes ${ }^{2}$-CRF-SP - $n^{\circ} 7731$

Lígia Pedroso Boretti ${ }^{1}$ - CRMV-SP - n ${ }^{0} 1769$

Mércia Rodrigues Barros ${ }^{3}$ - CRMV-SP - n 11980

Sandro Roberto Del Bem ${ }^{3}$-CRMV-SP-n ${ }^{\circ} 9957$

Adriano Fontana ${ }^{3}$ - CRMV-SP- ${ }^{\circ} 10020$

Homero Marcos Sampaio ${ }^{3}$-CRMV-SP - n 9775

Edson Naoto Savano ${ }^{3}$ - CRMV-SP - n ${ }^{\circ} 8896$

1 Docentes de Ornitopatologia do Departamento de Clínica Veterinária - FMVZ - UNESP/Botucatu/SP.

2 Pesquisadora Científica da Seção de Bacteriologia - Setor de Enterobactérias - Instituto Adolfo Lutz/São Paulo/SP.

3 Médicos Veterinários Residentes do Serviço de Ornitopatologia do Departamento de Clínica Veterinária - FMVZ - UNESP/Botucatu/SP.

\section{RESUMO}

Foram identificados os sorovares de Salmonella isolados de materiais avícolas, provenientes de diferentes áreas geográficas, durante o período de 1994 a 1999. Isolaram-se 73 sorovares no total, com reconhecimento de 21 sorovares diferentes, distribuídos em nove sorogrupos. O sorovar de maior incidência com $46,52 \%$ foi o enteritidis, proveniente de órgãos de frangos de corte, poedeiras e matrizes pesadas, embora não tenha sido isolado de ração, cama e nas farinhas de carne, de vísceras ou de peixe. O segundo sorovar de maior incidência foi o anatum com $6,84 \%$, sendo que $80 \%$ do seu isolamento ocorreu em farinha de carne. A S. pullorum representou $2,73 \%$ dos isolamentos, ocorridos $100 \%$ em poedeiras vermelhas, confirmando sua maior susceptibilidade em relação à infecção por este sorovar. Frango de corte e farinha de carne foram os materiais analisados em que mais se encontraram Salmonella spp., com 41,09 e 30,13\%, respectivamente, dos diferentes sorovares. Entre os sorovares isolados de frangos de corte, $83,34 \%$ corresponderam ao enteritidis, enquanto em farinha de carne este mesmo sorovar não foi detectado. A área geográfica responsável pelo maior isolamento de Salmonella spp. foi o Estado de São Paulo com 82,19\%, seguido seqüencialmente pelo Estado do Maranhão com 8,21\%. O Estado de São Paulo foi responsável por 79,41\% do isolamento de $S$. enteritidis. Apesar de o sorogrupo 0:9,12 apresentar o marior número de isolamentos justamente por nele estar inserido o sorovar de maior prevalência, o enteritidis, foi o sorogrupo 0:6,7 que apresentou a maior variação de sorovares. Demonstramos a importância do rastreamento epidemiológico da Salmonella em relação a indústria avícola, em virtude da importante posição das aves dentro da cadeia alimentar e do ciclo de propagação desta bactéria, envolvendo não só a sanidade avícola, mas também a saúde pública.

Palavras-chave: Salmonella, aves, sorovares, sorogrupos, isolamento. 


\section{Introdução}

A incidência de infecção alimentar por Salmonella spp. vem aumentando em várias partes do mundo, apesar de todo o desenvolvimento tecnológico na produção de alimentos e da adoção de melhores medidas higiênicas. Os alimentos de origem animal continuam a ser os principais responsáveis pela infecção humana, entre eles, a carne de aves, ovos e derivados. Entre todas as espécies animais, a presença de Salmonella spp. é mais freqüentemente descrita em aves e também em produtos de origem aviária, por ser uma população de alto risco e pelos intensos controle exercido pelas agroindústrias e instituições no isolamento e identificação desta bactéria (HUMPHREY, 1990; GAST, 1997).

A salmonelose humana é um relevante problema de saúde pública, originado na ingestão de alimentos contaminados e/ou indevidamente preparados. A carne de aves é freqüentemente contaminada por Salmonella spp., que é transferida do conteúdo intestinal para a carcaça durante o processamento industrial (McGARR et al., 1980; KVENBERG; ARCHER, 1987; RAMPLING et al., 1989). Também os ovos, consumidos crus, semi-cozidos ou como ingredientes de alimentos mal preparados, foram identificados como responsáveis por surtos de toxiinfecção humana relacionados com Salmonella spp (St. LOUIS et al., 1988; EBEL et al., 1993; GAST, 1994; HENZLER et al., 1994; JONES et al., 1995). As aves de criação industrial contaminam-se por Salmonella spp., geralmente, pela transmissão vertical via ovo ou, no seu ambiente de criação, via ração, roedores e outros animais. A presença comum de Salmonella spp. na ração, na farinha de carne ou de pena e em vísceras, secreções de roedores, insetos e na cama do aviário, aumenta e sustenta índices de contaminação cada vez maiores nos plantéis avícolas (ÁVILA et al., 1972; HACKING et al., 1978; BERCHIERI JÚNIOR et al., 1984, 1989; HENZLER; OPITZ, 1992; BERCHIERI JÚNIOR et al., 1993; KOPANIC JUNIOR et al., 1994; DAVIES; WRAY, 1995; VELDMAN et al., 1995). No presente trabalho, demonstramos os sorovares de Salmonella isolados de diferentes materiais avícolas, enviados de diferentes áreas geográficas para análise no Laboratório de Ornitopatologia da Faculdade de Medicina Veterinária e Zootecnia (FMVZ) da Universidade Estadual Paulista (UNESP), Campus de Botucatu - SP, durante o período de 1994 a 1999, possibilitando um breve estudo epidemiológico da distribuição dos sorovares de Salmonella encontrados, em relação especialmente ao material avícola analisado.

\section{Material e Métodos}

O Laboratório de Ornitopatologia da FMVZ UNESP - Campus de Botucatu - SP., recebe regularmente material avícola proveniente de agroindústrias de diversas áreas geográficas, para tentativa de isolamento e detecção de Salmonella spp. Durante o período de janeiro de 1994 a dezembro de 1999, todos os sorovares isolados e identificados de Salmonella, provenientes de material avícola, foram catalogados conforme a área geográfica, o material avícola e o sorogrupo ao qual pertenciam os sorovares.

As amostras para isolamento foram encaminhadas principalmente por agroindústrias, frigoríficos e, em menor escala, por instituições públicas e granjas avícolas de pequeno porte.

Durante o período descrito, somente aves de produção (Gallus gallus) acusaram a presença de sorovares de Salmonella, variando conforme a finalidade de criação, ou seja, matrizes pesadas, poedeiras e frangos de corte. Os órgãos de eleição para isolamento foram o fígado, a vesícula biliar, o coração, o saco vitelino, os cecos, o baço, o ovário e o oviduto. As aves foram recebidas vivas ou congeladas, no laboratório. Quando vivas, procedeu-se ao sacrifício seguido de necropsia.

Carcaças de frangos resfriadas, proveniente de abatedouros, foram recebidas nas embalagens comerciais originais.

Outros materiais, como ração, farinha de carne (bovina), farinha de vísceras (aves), farinha de peixe e cama de aviários (frango de corte), foram recebidos em sacos plásticos contendo geralmente de um a dois quilogramas do material à temperatura ambiente.

Todos os materiais foram cultivados visando o isolamento de Salmonella spp. conforme metodologia consagrada (MALLINSON; SNOEYENBOS, 1989). Todos os órgãos utilizados para isolamento foram cuidadosa e assepticamente retirados das carcaças das aves e triturados individualmente ou em "pool" do mesmo órgão. Porções de um a dois gramas de cada macerado foram colocadas em tubos de ensaio contendo $10 \mathrm{ml}$ de caldos seletivos de enriquecimento, como caldo tetrationato e caldo selenito cistina a $40^{\circ} \mathrm{C}$ durante 24 e 48 horas.

Carcaças ou aves evisceradas foram depositadas inteiras e individualmente em sacos plásticos contendo $300 \mathrm{ml}$ de água peptonada tamponada. Após agitação e lavagem durante cinco minutos, o caldo resultante foi transferido a um "erlenmayer" estéril e incubado a $40^{\circ} \mathrm{C}$ durante 24 horas. Alíquotas de $1 \mathrm{ml}$ deste caldo foram transferidas para os caldos seletivos de enriquecimento, seguindo o mesmo procedimento dos demais materiais. 

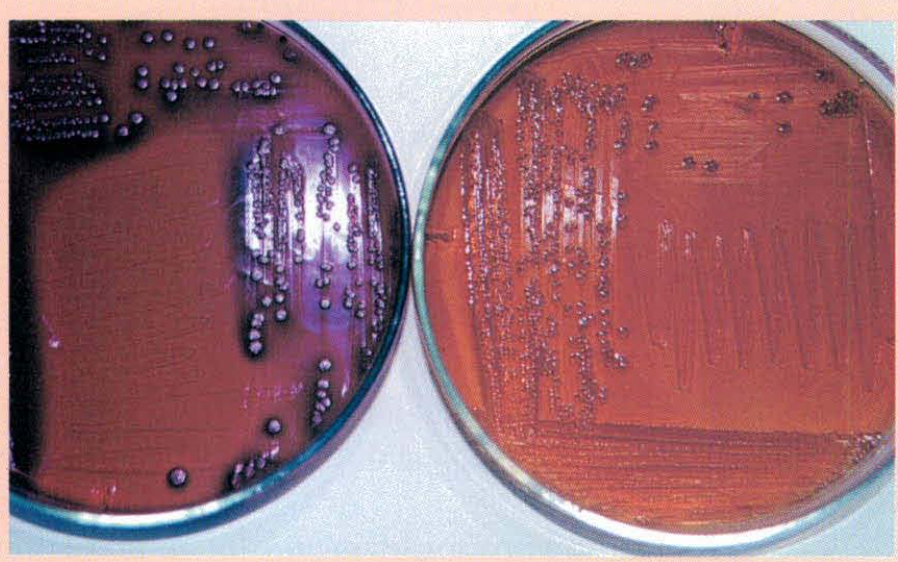

Figura 1. Colônias bacterianas desenvolvidas em placas de Petri contendo ágar MacConkey. Na placa da direita, onde foi semeada cepa de Salmonella enteritidis, há a presença de colônias incolores e translúcidas, características de Salmonella spp., enquanto na placa da esquerda, onde foi semeada cepa de Escherichia coli, há colônias com intensa coloração rosa, característica de bactéria fermentadora de lactose.

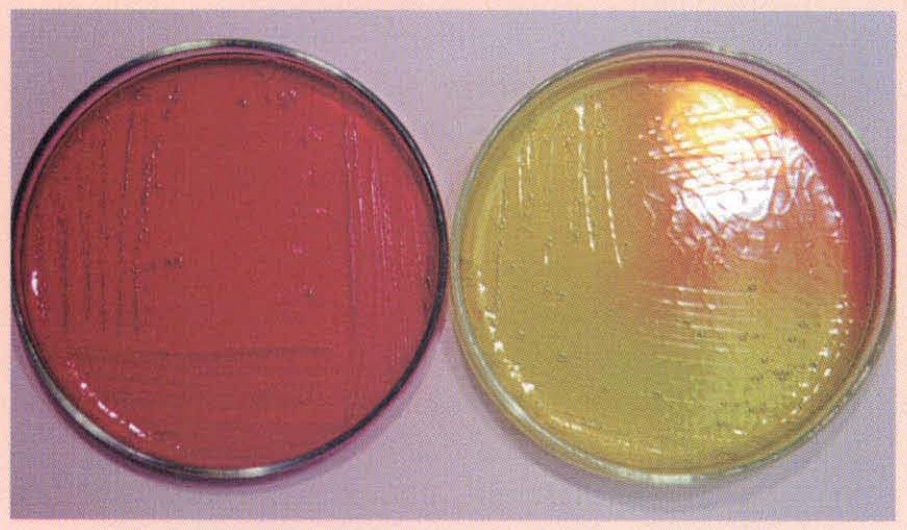

Figura 2. Colônias bacterianas desenvolvidas em placas de Petri contendo ágar verde brilhante. Na placa da esquerda, onde foi semeada cepa de Salmonella enteritidis, há a presença de colônias rosáceas ligeiramente opacas, características de Salmonella spp., enquanto na placa da direita, onde foi semeada cepa de Escherichia coli, há colônias verde-amareladas, característica de bactéria fermentadora de lactose.
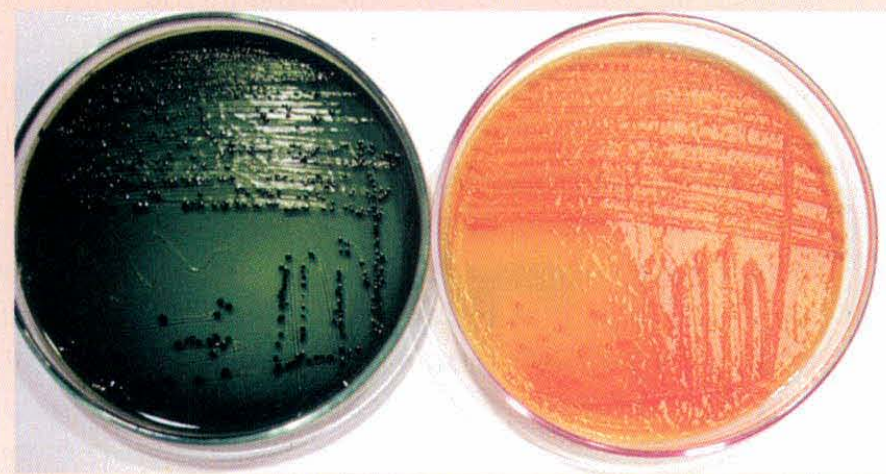

Figura 3. Colônias bacterianas desenvolvidas em placas de Petri contendo ágar entérico de Hektoen. Na placa da esquerda, onde foi semeada cepa de Salmonella enteritidis, há a presença de colônias verde-azuladas com o centro preto (produção de $\mathrm{H}_{2} \mathrm{~S}$ ), características de Salmonella $s p p$., enquanto na placa da direita, onde foi semeada cepa de Escherichia coli, há colônias com coloração salmão, característica de bactéria fermentadora de lactose e/ou sacarose.
Materiais diferentes de órgãos e carcaças foram pré-enriquecidos em caldo não seletivo (água peptonada tamponada) na quantidade de $25 \mathrm{~g}$ do material e $225 \mathrm{ml}$ de água peptonada tamponada, incubados a $40^{\circ} \mathrm{C}$ durante 24 horas, dos quais se retiraram alíquotas de $1 \mathrm{ml}$, que foram transferidas para os caldos seletivos de enriquecimento, tetrationato e selenito cistina e, incubadas a $40^{\circ} \mathrm{C}$, durante 24 e 48 horas. A partir dessa seqüência, todos os materiais seguiram o mesmo procedimento. Alçadas dos caldos tetrationato e selenito cistina, após agitação, foram estriadas em duplicata de placas de Petri contendo ágar MacConkey, ágar verde brilhante e ágar entérico de Hektoen, para plaqueamento seletivo diferencial, incubados durante 24 horas, à temperatura de $40^{\circ} \mathrm{C}$. As colônias desenvolvidas nas placas com características de $\mathrm{Sal}$ monella spp., ou seja, colônias incolores e translúcidas no ágar MacConkey, colônias rosáceas translúcidas ou ligeiramente opacas em ágar verde brilhante e colônias verde-azuladas com ou sem o centro preto em ágar entérico de Hektoen (Figuras 1, 2, e 3) foram repicadas em bateria bioquímica composta de ágar tríplice açúcar ferro (Figura 4), ágar lisina ferro, ágar sulfeto, indol e motilidade (Figura 5), ágar motilidade, caldos lactose, sacarose, manitol, maltose, dulcitol, salicina, sorbitol, adonitol (Figuras 6 e 7), caldo para descarboxilação de lisina e arginina, ágar citrato de Simmons, caldo Voges-Proskauer, caldo vermelho de metila e caldo uréia (Figura 8). Colônias bacterianas cóm características bioquímicas compatíveis com Salmonella spp. foram então submetidas à sorologia pela exposição a soro polivalente anti-Salmonella spp. somático (Poli O) e soro polivalente anti-Salmonella spp. flagelar (Poli H). Amostras positivas também na sorologia, foram encaminhadas em ágar nutriente ao Instituto Adolfo Lutz - São Paulo SP., para sorotipagem. Seguiu-se a orientação de LE MINOR; POPOFF (1987), para a grafia dos sorovares.

\section{Resultados}

De todo o material avícola enviado para a detecção e a identificação de Salmonella spp. ao Laboratório de Ornitopatologia da FMVZ - UNESP, no período de 1994 a 1999, isolaram-se 73 sorovares no total, com reconhecimento de 21 sorovares diferentes, entre os quais se incluem as variantes sorológicas e a forma rugosa (Tabela 1). 
O sorovar de maior incidência foi o Enteritidis, que atingiu 46,57\% no período. Ressalte-se que este sorovar foi detectado apenas nos órgãos de matrizes pesadas, poedeiras, frangos de corte e, também, em carcaça de frango, embora não tenha sido isolado de ração, cama e nas farinhas de carne, de vísceras ou de peixe. É interessante assinalar que, enquanto o sorovar Enteritidis foi o mais isolado, a farinha de carne foi o material analisado em que mais se encontrou Salmonella spp $(30,13 \%)$, excetuando-se os frangos de corte e, em nenhuma das amostras de farinha de carne, detectou-se $S$. enteritidis (Tabela 1).

O segundo sorovar de maior incidência foi o anatum com $6,84 \%$, posicionando-se muito aquém da $S$. Enteritidis e com seu isolamento $(80 \%)$ quase inteiramente detectado na farinha de carne. Seqüencialmente, com a incidência variando de 2,73 a $5,47 \%$, observaram-se os sorovares mbandaka, senftenberg, montevideo, cubana, bredeney, agona e pullorum. Mais uma vez a farinha de carne foi o material de maior incidência, com exceção dos sorovares mbandaka e pullorum. Todos os demais sorovares: dublin, schoeneberg, rissen, tennessee, alachua, livingstone, orion, ouakam, amostras da subespécie I e rugosas, representaram $17,69 \%$ do total de sorovares isolados, dos quais $69,23 \%$ foram provenientes da farinha de carne (Tabela 1 e Figura 9).

$\mathrm{O}$ material de maior incidência foram as vísceras dos frangos de corte com $41,09 \%$, seguido pela farinha de carne com $30,13 \%$, poedeiras com $10,95 \%$, matrizes com $5,47 \%$ e carcaça de frango e farinha de peixe com $4,1 \%$ cada. A ração, a farinha de vísceras e a farinha de peixe e a cama dos aviários representaram $1,36 \%$ de incidência cada uma (Tabela 1 e Figura 10).

A área geográfica responsável pelo maior isolamento de Salmonella spp. foi o Estado de São Paulo com $82,19 \%$, seguido seqüencialmente pelos Estados do Maranhão com $8,21 \%$, Paraná com 5,47\%, Pernambuco com $2,73 \%$ e um único sorovar (mbandaka) proveniente da cidade de Assunção no Paraguai com 1,36\% (Tabela 2). Com exceção do sorovar schoeneberg, todos os demais foram detectados no Estado de São Paulo. O Estado de São Paulo foi responsável por $79,41 \%$ do isolamento de $S$. enteritidis, enquanto o Estado do Maranhão apresentou $17,64 \%$ de isolamento deste mesmo sorovar. O Estado de Pernambuco com 2,94\% do isolamento ocupou a terceira posição. O Estado do Paraná e a cidade de Assunção (Paraguai) não apresentaram este sorovar (Tabela 2).

Analisando somente o Estado de São Paulo, verificamos que das 60 amostras isoladas nele, $45,0 \%$ são referentes ao sorovar enteritidis, $8,34 \%$ ao sorovar anatum, $5,0 \%$ aos sorovares montevideo e cubana, 3,34\% aos sorovares mbandaka, senftenberg, bredeney, agona, pullorum e subespécie I rugosa, e 1,67\% a todos os demais sorovares individualmente, com exceção do schoeneberg (Tabela 2).

A maior variação dos sorovares não esteve no sorogrupo com o maior número de isolamentos, ou seja, o sorogrupo $0: 9,12$ foi o responsável por $52,02 \%$ dos isolamentos com apenas quatro sorovares distintos, enquanto o O:6,7, com 16,38\% dos isolamentos, apresentou seis sorovares diferentes. Essa diversidade deve-se ao fato de que no sorogrupo 0:9,12 está inserido o sorovar enteritidis, que sozinho, foi o responsável por $46,57 \%$ dos isolamentos (Tabela 3 e Figura 11).

Seqüencialmente ao sorogrupo O:9,12 com $52,02 \%$ dos sorovares isolados, observam-se os soro- 


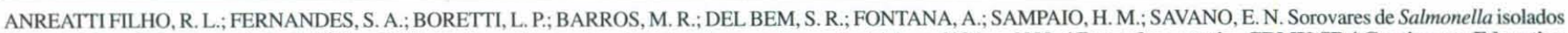

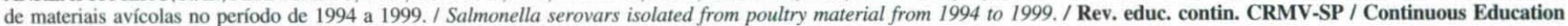
Journal CRMV-SP, São Paulo, volume 4, fascículo 3, p. 90 - 101, 2001.

Tabela 1. Distribuição por material analisado dos sorovares de Salmonella isolados no período de 1994 a 1999, no Laboratório de Ornitopatologia da FMVZ - UNESP - Campus de Botucatu.

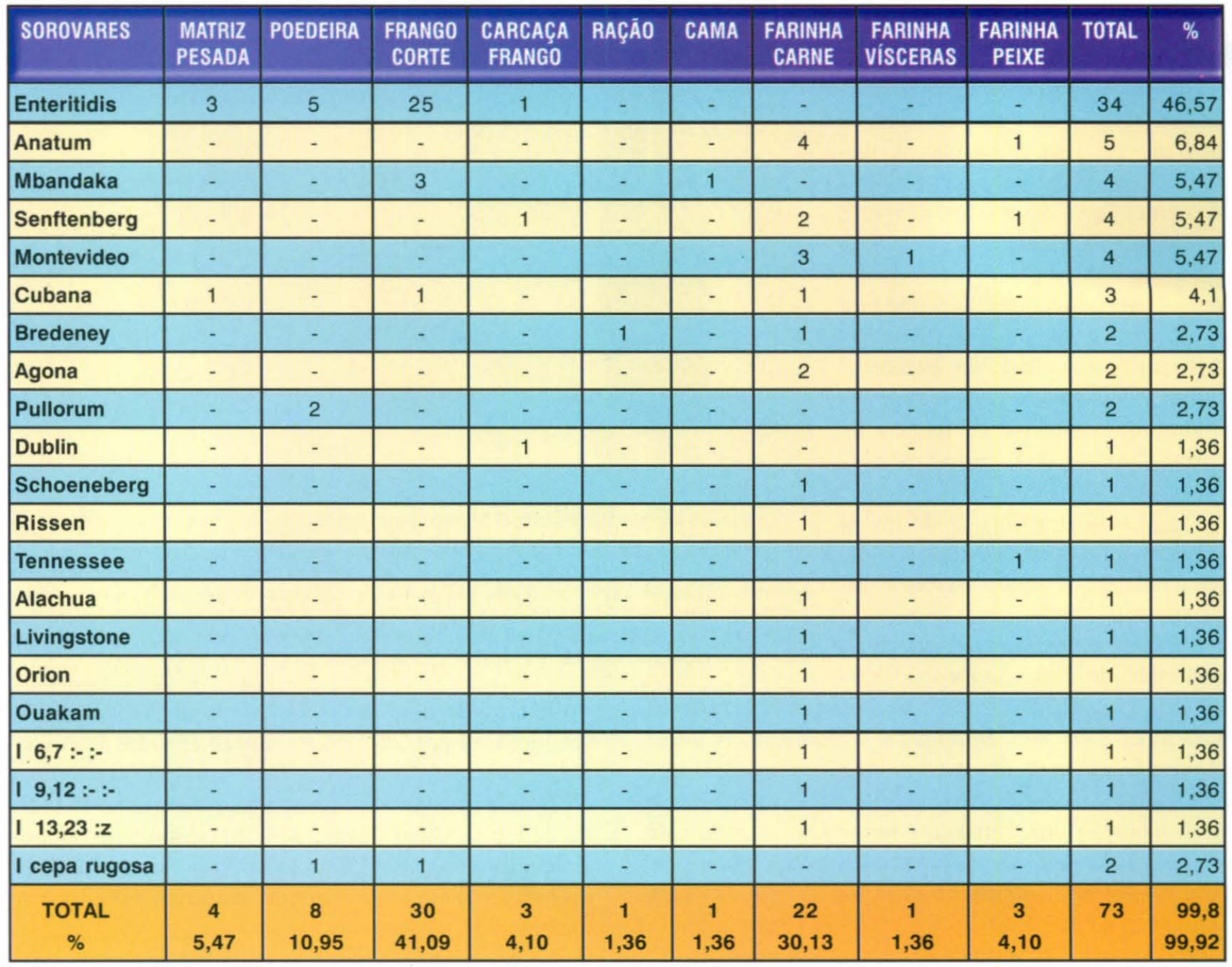

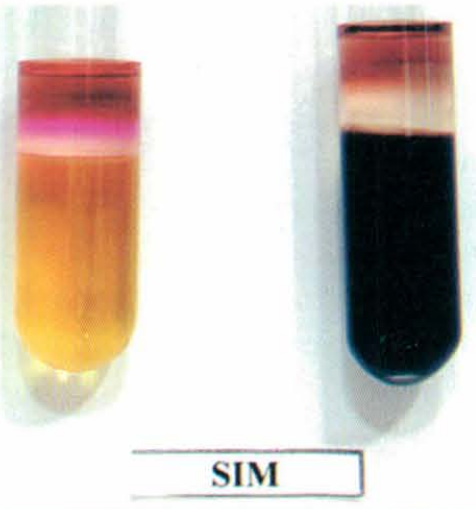

Figura 5. Teste de indol - ágar sulfeto, indol e motilidade. O tubo da esquerda foi semeado com cepa de Escherichia coli e houve o desenvolvimento de anel vermelho-violeta na superfície do meio de cultura (indol positivo). O tubo da direita foi semeado com cepa de Salmonella enteritidis e o anel permaneceu amarelado (indol negativo), compatível com Salmonella spp. Observar produção de $\mathrm{H}_{2} \mathrm{~S}$ (escurecimento do ágar) no tubo da direita, também compatível com Salmonella spp. grupos O:67 com 16,38\%; O:3,10 com 8,2\%; O:1,3,19 com $6,83 \%$; O:4 e O:13,23 com $5,46 \%$; rugosa com $2,73 \%$ e $0: 9,46$ e O:35 com $1,36 \%$ em ambos (Tabela 3 e Figura 11).

\section{Discussão}

A colonização da mucosa intestinal por grande e diversificado número de bactérias é achado normal em diversas espécies animais, incluindo as aves (LEE, 1985). Nesse grupo de bactérias podemos encontrar diferentes sorovares de Salmonella, podendo acarretar tanto a salmonelose aviária quanto a humana, quando da ingestão de produtos avícolas contaminados. A salmonelose aviária é o termo que designa um grande grupo de doenças aviárias agudas ou crônicas causadas por um ou mais membros do gênero 


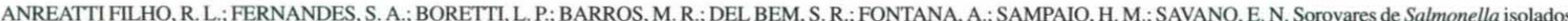

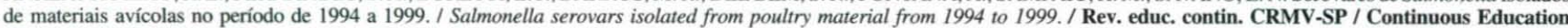
Journal CRMV-SP, São Paulo, volume 4, fascículo 3, p. 90 - 101, 2001.

Tabela 2. Distribuição conforme a área geográfica dos sorovares de Salmonella isolados no período de 1994 a 1999 , no Laboratório de Ornitopatologia da FMVZ - UNESP

\begin{tabular}{|c|c|c|c|c|c|c|c|}
\hline \multirow[b]{2}{*}{ SOROVARES } & \multicolumn{5}{|c|}{ ORIGEM } & \multirow[b]{2}{*}{ TOTAL } & \multirow[b]{2}{*}{$\%$} \\
\hline & $\begin{array}{l}\text { ASSUNCÃO } \\
\text { (PARAGUAI) }\end{array}$ & MARANHĀO & PARANÁ & PERNAMBUCO & $\begin{array}{l}\text { SÃO } \\
\text { PAULLO }\end{array}$ & & \\
\hline Enteritidis & - & 6 & - & 1 & 27 & 34 & 46,57 \\
\hline Anatum & - & - & - & - & 5 & 5 & 6,84 \\
\hline Mbandaka & 1 & - & - & 1 & 2 & 4 & 5,47 \\
\hline Senftenberg & - & - & 2 & - & 2 & 4 & 5,47 \\
\hline Montevideo & - & - & 1 & - & 3 & 4 & 5,47 \\
\hline Cubana & - & - & - & - & 3 & 3 & 4,1 \\
\hline Bredeney & - & - & - & - & 2 & 2 & 2,73 \\
\hline Agona & - & - & - & - & 2 & 2 & 2,73 \\
\hline Pullorum & - & - & - & - & 2 & 2 & 2,73 \\
\hline Dublin & - & - & - & - & 1 & 1 & 1,36 \\
\hline Schoeneberg & - & - & 1 & - & - & 1 & 1,36 \\
\hline Rissen & - & - & - & - & 1 & 1 & 1,36 \\
\hline Tennessee & - & - & - & - & 1 & 1 & 1,36 \\
\hline Alachua & - & - & - & - & 1 & 1 & 1,36 \\
\hline Livingstone & - & - & - & - & 1 & 1 & 1,36 \\
\hline Orion & - & - & - & - & 1 & 1 & 1,36 \\
\hline Ouakam & - & - & - & - & 1 & 1 & 1,36 \\
\hline S. 16,7 :-:- & - & - & - & - & 1 & 1 & 1,36 \\
\hline S. 19,12 :-:- & - & - & - & - & 1 & 1 & 1,36 \\
\hline S. I 13,23:z & - & - & - & - & 1 & 1 & 1,36 \\
\hline S. I rugosa & - & - & - & - & 2 & 2 & 2,73 \\
\hline $\begin{array}{c}\text { TOTAL } \\
\%\end{array}$ & $\begin{array}{c}1 \\
1,36\end{array}$ & $\begin{array}{c}6 \\
8,21\end{array}$ & $\begin{array}{c}4 \\
5,47\end{array}$ & $\begin{array}{c}2 \\
2,73\end{array}$ & $\begin{array}{c}60 \\
82,19\end{array}$ & 73 & $\begin{array}{c}99,8 \\
99,96\end{array}$ \\
\hline
\end{tabular}

Salmonella. Doenças determinadas por sorovares hospedeiro-específicos, como a pulorose, causada por $S$. pullorum e o tifo aviário, por $S$. gallinarum, bem como a infecção paratifóide, determinada pelos mais de 2300 sorovares restantes de Salmonella, especialmente $S$. enteritidis que, nas duas últimas décadas, é o sorovar responsável pelo maior número de surtos, seja em humanos, ou seja em aves, compõem o grupo de doenças aviárias denominado salmonelose.

Com a grande expansão da indústria avícola, a salmonelose aviária tornouse fator limitante na criação de aves, adquirindo importância relevante entre as de-

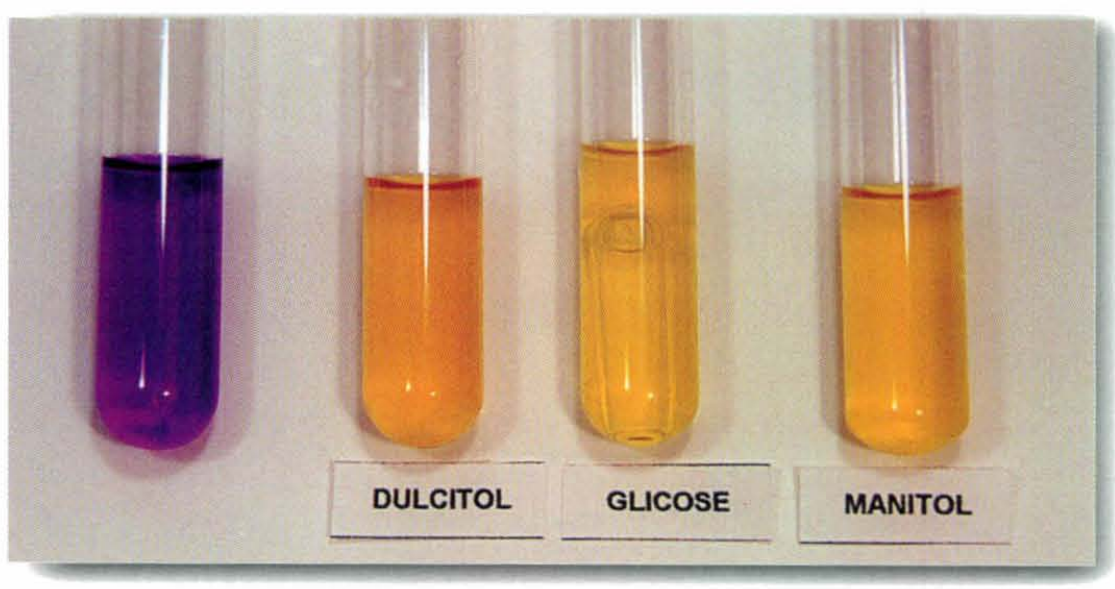

Figura 6. Teste de fermentação de carboidratos. Fermentação de dulcitol, glicose e manitol por cepa de Salmonella enteritidis. A positividade é determinada pela viragem ácida do indicador, alterando a cor do meio de vermelho-violeta para amarelo. O tubo controle da esquerda apresentase na cor original. Observar produção de gás em tubo de Durham no meio contendo glicose. 


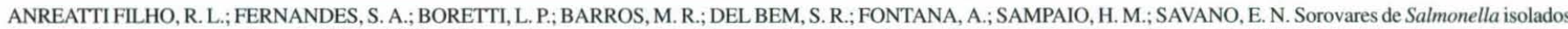

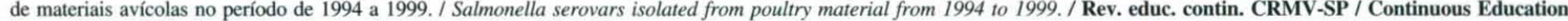
Journal CRMV-SP, São Paulo, volume 4, fascículo 3, p. 90 - 101, 2001

Tabela 3. Distribuição dos sorovares de Salmonella em relação aos seus sorogrupos, isolados no período de 1994 a 1999 , no Laboratório de Ornitopatologia da FMVZ - UNESP.

\begin{tabular}{|c|c|c|c|c|}
\hline SOROGRUPOS & SOROVARES & NÚMERO & $\begin{array}{c}\% \\
\text { SOROVARES }\end{array}$ & $\begin{array}{c}\% \\
\text { SOROGRUPOS }\end{array}$ \\
\hline $0: 4(B)^{a}$ & $\begin{array}{l}\text { Agona } \\
\text { Bredeney }\end{array}$ & $\begin{array}{l}2 \\
2\end{array}$ & $\begin{array}{l}2,73 \\
2,73\end{array}$ & 5,46 \\
\hline $0: 6,7\left(C_{1}\right)^{a}$ & $\begin{array}{l}\text { Mbandaka } \\
\text { Montevideo } \\
\text { Tennessee } \\
\text { Livingstone } \\
\text { Rissen } \\
\text { S. I 6,7 :-:-b }\end{array}$ & $\begin{array}{l}4 \\
4 \\
1 \\
1 \\
1 \\
1\end{array}$ & $\begin{array}{l}5,47 \\
5,47 \\
1,36 \\
1,36 \\
1,36 \\
1,36 \\
\end{array}$ & 16,38 \\
\hline $0: 9,12\left(D_{1}\right)^{a}$ & $\begin{array}{l}\text { Enteritidis } \\
\text { Pullorum } \\
\text { Dublin } \\
\text { S. I } 9,12 \text { :-:-b }\end{array}$ & $\begin{array}{l}34 \\
2 \\
1 \\
1\end{array}$ & $\begin{array}{c}46,57 \\
2,73 \\
1,36 \\
1,36\end{array}$ & 52,02 \\
\hline $0: 9,46\left(D_{2}\right)^{a}$ & Ouakam & 1 & 1,36 & 1,36 \\
\hline $0: 3,10\left(E_{1}\right)^{a}$ & $\begin{array}{l}\text { Anatum } \\
\text { Orion }\end{array}$ & $\begin{array}{l}5 \\
1\end{array}$ & $\begin{array}{l}6,84 \\
1,36\end{array}$ & 8,2 \\
\hline $0: 1,3,19\left(E_{4}\right)^{a}$ & $\begin{array}{l}\text { Senftenberg } \\
\text { Schoeneberg }\end{array}$ & $\begin{array}{l}4 \\
1\end{array}$ & $\begin{array}{l}5,47 \\
1,36\end{array}$ & 6,83 \\
\hline $0: 13,23\left(G_{2}\right)^{a}$ & $\begin{array}{l}\text { Cubana } \\
\text { S. I } 13,23: z^{b}\end{array}$ & $\begin{array}{l}3 \\
1\end{array}$ & $\begin{array}{l}4,10 \\
1,36\end{array}$ & 5,46 \\
\hline $0: 35(0)^{a}$ & Alachua & 1 & 1,36 & 1,36 \\
\hline Rugosa & Salmonella spp. & 2 & 2,73 & 2,73 \\
\hline Total & & 73 & 99,8 & 99,8 \\
\hline
\end{tabular}

a Representação anterior dos sorogrupos

b Salmonella subespécie I

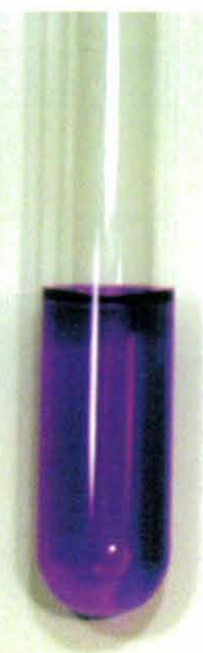

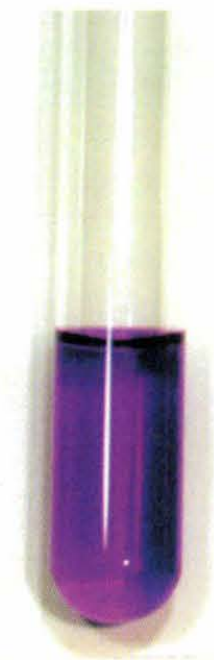

SALICINA

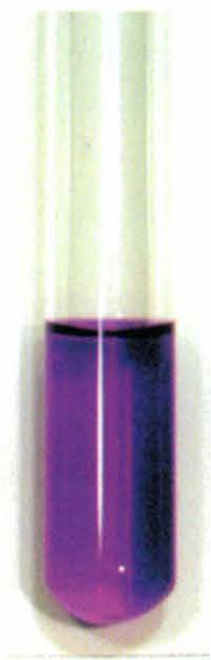

SACAROSE

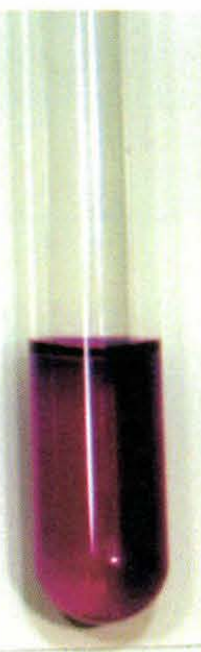

RAFINOSE
Figura 7. Teste de fermentação de carboidratos. A não fermentação de salicina, sacarose e rafinose por parte da cepa de Salmonella enteritidis, determina a manutenção da cor original do meio (vermelho-violeta) semelhante ao tubo controle (esquerda). mais doenças aviárias, pois as perdas econômicas determinadas por esta doença estão presentes em todas as fases da produção avícola, ou seja, da produção ao consumo dos produtos de origem aviária.

A pulorose e o tifo aviário encontram-se sob estrito controle na grande maioria dos países de avicultura desenvolvida, embora nos últimos anos surtos dessas doenças tenham aumentado em várias regiões do mundo, particularmente em países da América Latina. Em vários outros países, principalmente nos considerados de primeiro mundo, o relato de infecções paratifóides vêm ganhando espaço na imprensa geral e especializada como grave problema sanitário às criações avícolas e como causa de toxiinfecções humanas veiculadas por produtos avícolas contaminados (SOCKETT, 1991; BARROW, 1993; GAST, 1997). 
No período de 1970 a 1990 , a S. typhimurium foi o sorovar mais prevalente, entre aqueles identificados pelo Instituto Adolfo Lutz - SP., especialmente em infecção humana, período em que a $S$. enteritidis foi observada esporadicamente. Entretanto, no início desta década e, especialmente nos anos de 1994 e 1995, a $S$. enteritidis foi o sorovar mais identificado, a tal ponto de, no período de janeiro a junho de 1995 , ser isolado em $56,2 \%$ do material humano e $43,4 \%$ de origem não humana, no qual se incluem alimentos em geral e ovos (FERNANDES et al., 1995; TAUNAY et al., 1995). Estes dados são muito próximos aos observados no período de 1994 a 1999 no Laboratório de Ornitopatologia da FMVZ - UNESP, pois 46,57\% dos sorovares de Salmonella isolados neste período, correspondeu exatamente ao enteritidis. Quase a totalidade desse isolamento $(97,06 \%)$ deu-se em vísceras de aves de produção, ou seja, de matrizes pesadas, poedeiras e frangos de corte. Apenas 2,94\% dos sorovares de $S$. enteritidis foi obtido de carcaça de aves. Diversos trabalhos têm mostrado o aumento da incidência de $S$. enteritidis nos últimos anos em materiais relacionados com a produção avícola, ou seja, cama usada, carcaças e vísceras de aves, água e outros (HACKING et al., 1978; McGARR

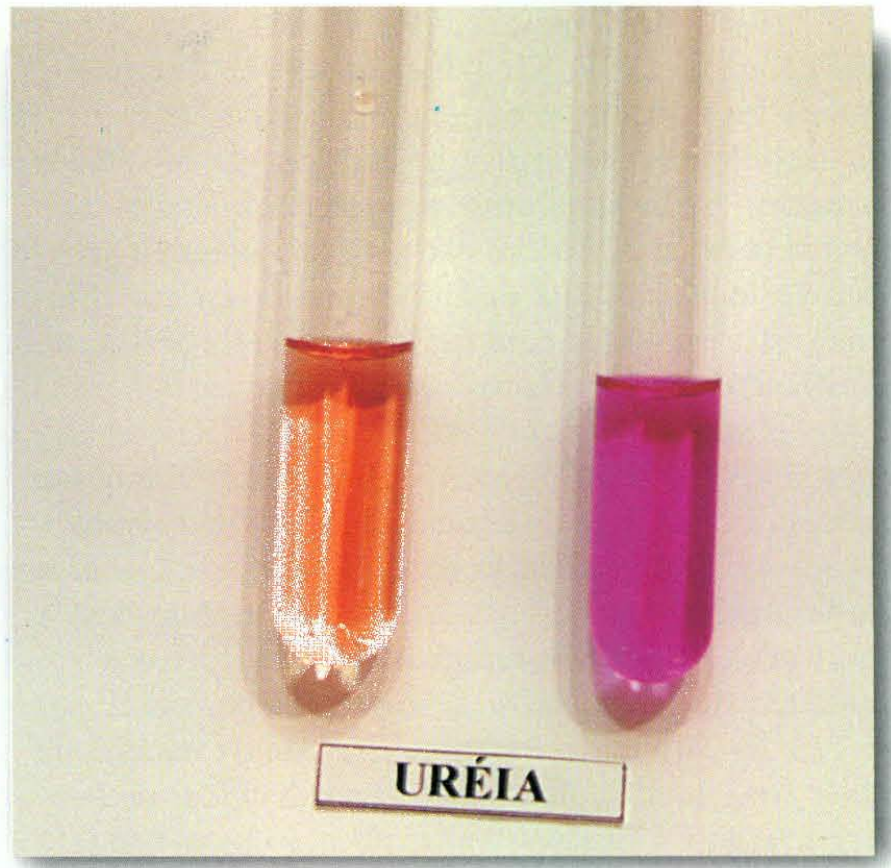

Figura 8. Teste de urease - caldo uréia. O tubo da esquerda foi semeado com cepa de Salmonella enteritidis e permaneceu com a cor original do meio - pêssego, caracterizando teste negativo, compatível com a maioria das cepas de Salmonella. O tubo da direita foi semeado com cepa de Proteus spp. e houve alteração da cor original para rosa escuro (teste positivo).

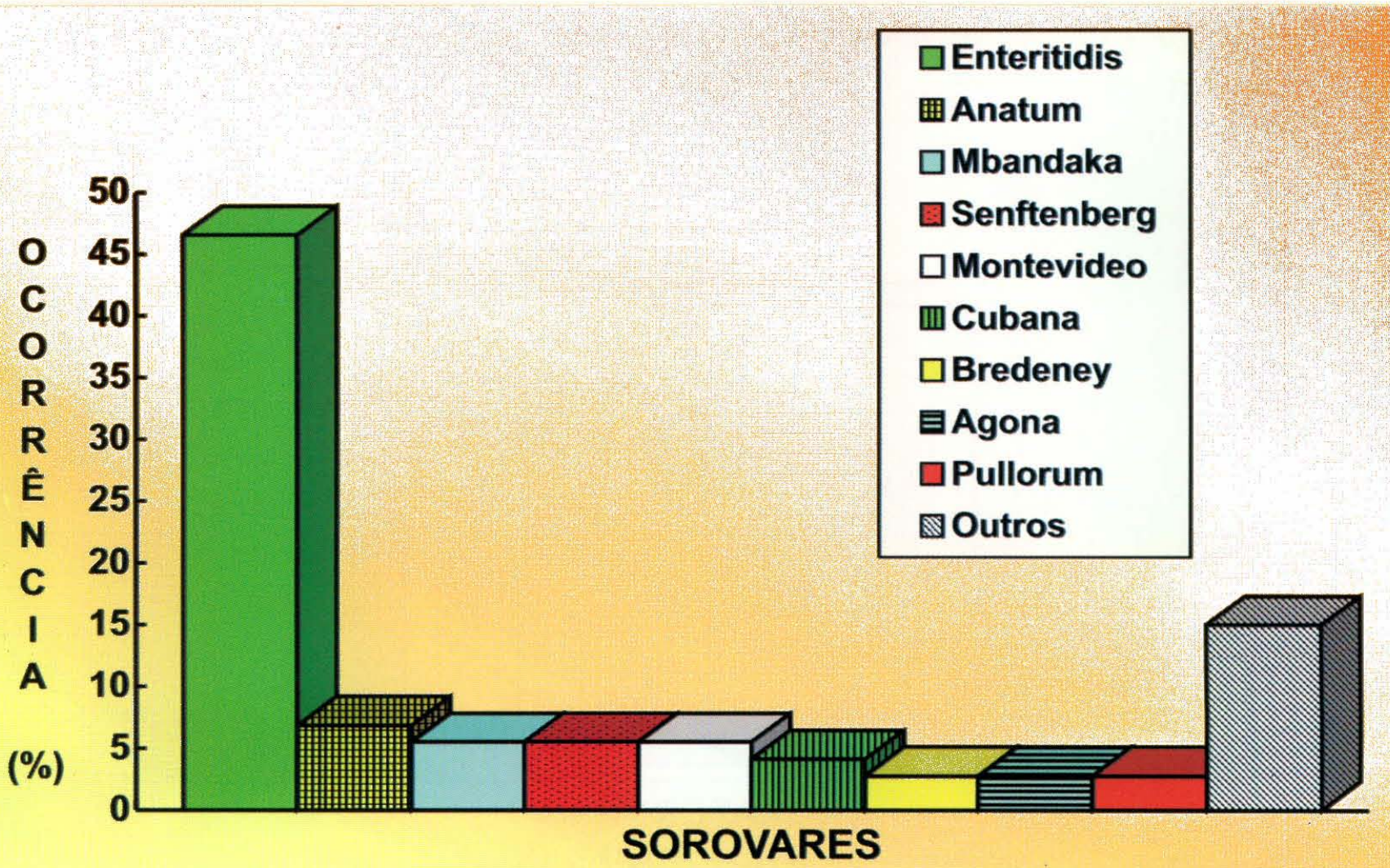

Figura 9. Detecção dos sorovares de Salmonella isolados de materiais avícolas enviados ao Laboratório de Ornitopatologia da FMVZ - UNESP - Campus de Botucatu, no período de 1994 a 1999. 


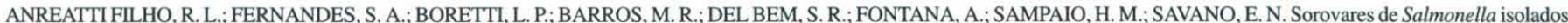

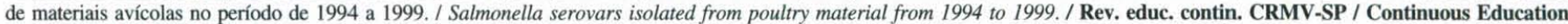
Journal CRMV-SP, São Paulo, volume 4, fascículo 3, p. 90 - 101, 2001

et al., 1980; HIRD et al., 1993; LÍRIO et al., 1995; HOFER et al., 1997; KINDE et al., 1997). Entretanto, embora historicamente exista correlação entre sorovares encontrados nas aves e posteriormente reisolados na matéria-prima para composição da própria ração consumida pelas aves, parece não ser fato comum o achado de $S$. enteritidis na matéria-prima, visto que diferentes rastreamentos com ração ou matéria-prima, no Brasîl ou mesmo em outros países, não acusaram o encontro deste sorovar (BERCHIERI JÚNIOR et al., 1984, 1989, 1993; VELDMAN et al., 1995). Em nosso Laboratório, no período assinalado, não houve nenhum isolamento de $S$. enteritidis proveniente de ração, cama ou de alguma das farinhas analisadas, mesmo com a farinha de carne sendo responsável por $30,13 \%$ dos isolamentos de Salmonella e, ainda, responsável por $71,42 \%$ dos diferentes sorovares isolados, e aqueles de maior freqüência, como anatum, montevideo, senftenberg e agona. Uma possível explicação para este fato seria a adaptação da $S$. Enteritidis ao hospedeiro, no caso as aves, pois raramente se encontra o sorovar que pode causar mortalidade intensa e aguda em aves jovens, sobrevivendo fora da ave. A presença de plasmídeos (POPPE; GYLES, 1987; EBEL et al., 1993), grau de invasibilidade (BARROW; LOVELL, 1991), a presença de fímbrias (DUGUID et al., 1979; ASLANZA-
DEH; PAULISSEN, 1992), a produção de citotoxina (REITMEYER et al., 1986; ASHKENAZI et al., 1988), produção de enterotoxina (JIWA, 1981) e a ação do lipídio A (CRAVEN, 1994) são alguns dos fatores de patogenicidade, possivelmente relacionados com esta maior especificidade em função do hospedeiro.

Os sorovares mais freqüentes, especialmente na farinha de carne, foram semelhantes aos relatados em outros rastreamentos epidemiológicos no Brasil, ou mesmo no exterior. S. anatum, S. montevideo, S. senftenberg e $S$. agona são sorovares extremamente presentes, sendo comumente encontrados em matéria-prima, ração e dieta de maneira geral (HACKING et al., 1978; BERCHIERI JÚNIOR et al., 1984, 1989, 1993; FALCÃO et al., 1993; VELDMAN et al., 1995). O grande número de sorovares encontrado na farinha de carne reforça que a contaminação da matéria-prima/ração seja causa primária da transmissão de Salmonella (BERCHIERI JÚNIOR et al., 1989, 1993; HOFER et al., 1997). Mesmo considerando que as origens dos materiais enviados para análise no nosso Laboratório sejam diferentes, com exceção da detecção de $S$. senftenberg em carcaça uma única vez e em farinha de carne, duas vezes, não houve correlação entre os sorovares isolados da ração e principalmente da matéria-prima com aqueles isolados das vísceras das aves. O reduzido número de isolamentos

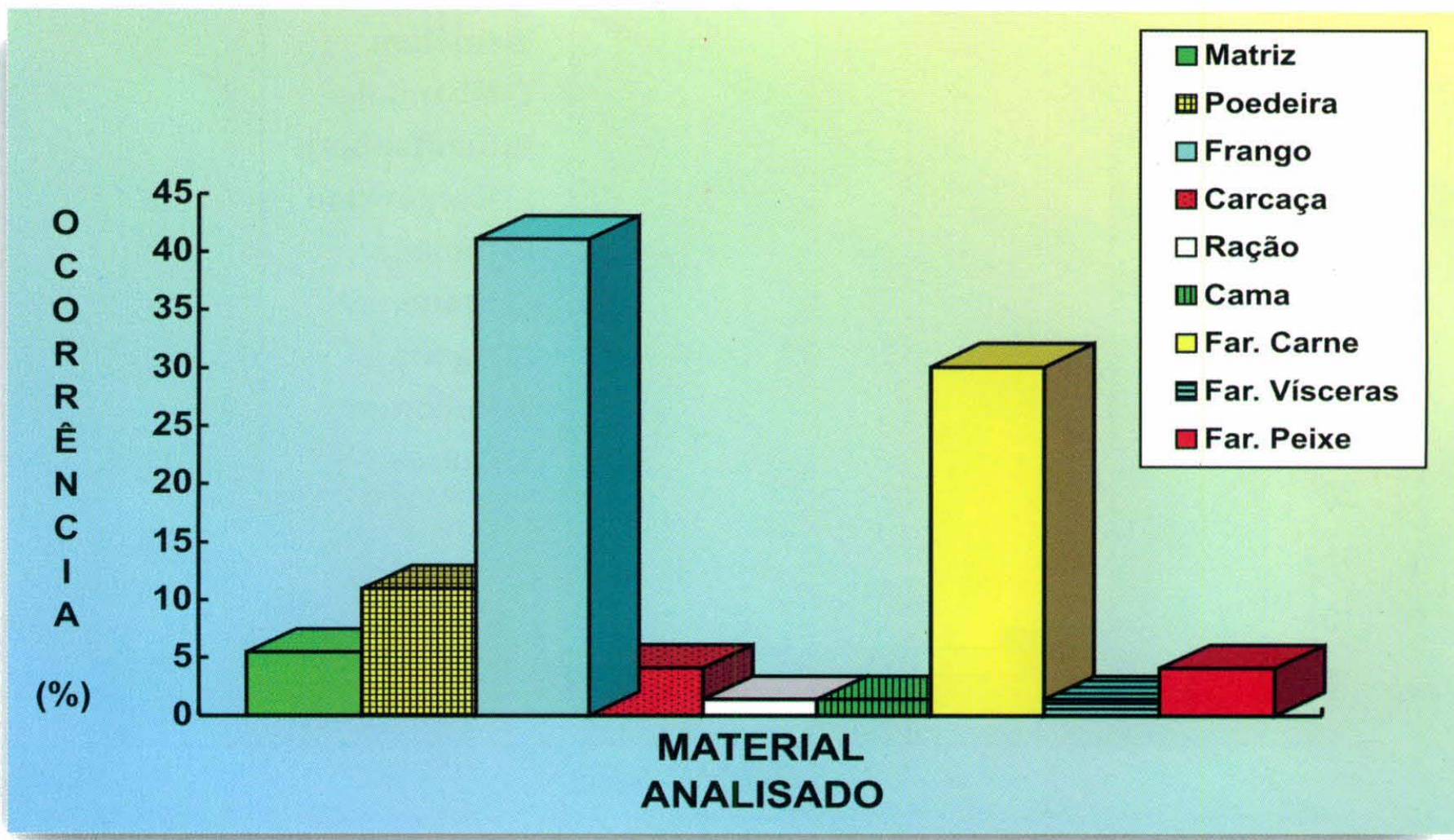

Figura 10. Distribuição do material avícola analisado, responsável pelo isolamento dos sorovares de Salmonella no Laboratório de Ornitopatologia da FMVZ - UNESP - Campus de Botucatu, no período de 1994 a 1999. 
proveniente de farinha de vísceras $(1,36 \%)$ deve-se diretamente a menor quantidade de amostras deste material analisadas no período.

Frangos de corte com $41,09 \%$ e, seqüencialmente farinha de carne com $30,13 \%$, poedeiras com $10,95 \%$ e matrizes com $5,47 \%$ foram os materiais que mais contribuíram para o isolamento de Salmonella. Aparentemente, a biosseguridade e o manejo impostos aos plantéis de matrizes foram os fatores moderadores para uma menor contaminação por Salmonella, em relação tanto a frango de corte quanto das poedeiras. Entretanto, enquanto $62,5 \%$ e $83,34 \%$ dos sorovares respectivamente isolados de poedeiras e frangos de corte foram de $S$. enteritidis, em matrizes, este número representou $75 \%$, ressaltando a importância e a implicação deste sorovar nas reprodutoras, especialmente no que tange à transmissão transovariana. A S. pullorum, um sorovar hospedeiro específico em aves, representou $2,73 \%$ dos isolamentos, ocorridos $100 \%$ em poedeiras vermelhas, confirmando sua maior susceptibilidade em relação a infecção por este sorovar. A detecção de $S$. pullorum demonstra que a pulorose/ tifo aviário, embora seja um programa de biosseguridade cada vez mais presente no combate a essas doenças avícolas, não deixaram de existir, mostrando, com isso, uma situação enzoótica, como relatada por HOFER et al. (1997).
Embora não tenha havido correlação entre quase todos os sorovares isolados de matéria-prima e vísceras das aves, esta existiu entre a cama e frango de corte com a $S$. mbandaka e entre a ração e farinha de carne com a $S$. bredeney. A alta incidência de Salmonella encontrada na farinha de carne, em comparação com o observado na ração, provavelmente deve-se a que nesta última sejam realizados processos de peletização ou acidificação, com a conseqüente redução da carga microbiana.

Apesar de não aparecer em resultados em razão da ausência de isolamento da Salmonella, ovos de consumo e bicados vivos ou mortos foram analisados inúmeras vezes. Esta ausência da Salmonella nos diversos tipos de ovos, coincide com o relato de que mesmo lotes naturalmente infectados com Salmonella, especialmente enteritidis, o nível de contaminação interna dos ovos é geralmente baixo, muitas vezes não ultrapassando 1\% (HUMPHREY et al., 1991; JONES et al., 1995), embora paralelamente ao exame interno, temos como rotina a análise também da casca, como possível fonte de contaminação.

O fato de o Estado de São Paulo ter apresentado $82,19 \%$ dos sorovares isolados é relevante, mostrandose-lhes a grande diversidade nos diversos materiais analisados, embora deva ser considerado que este Estado tenha sido responsável pela maior parte do material enviado para análise. Outro aspecto observado foi o Estado

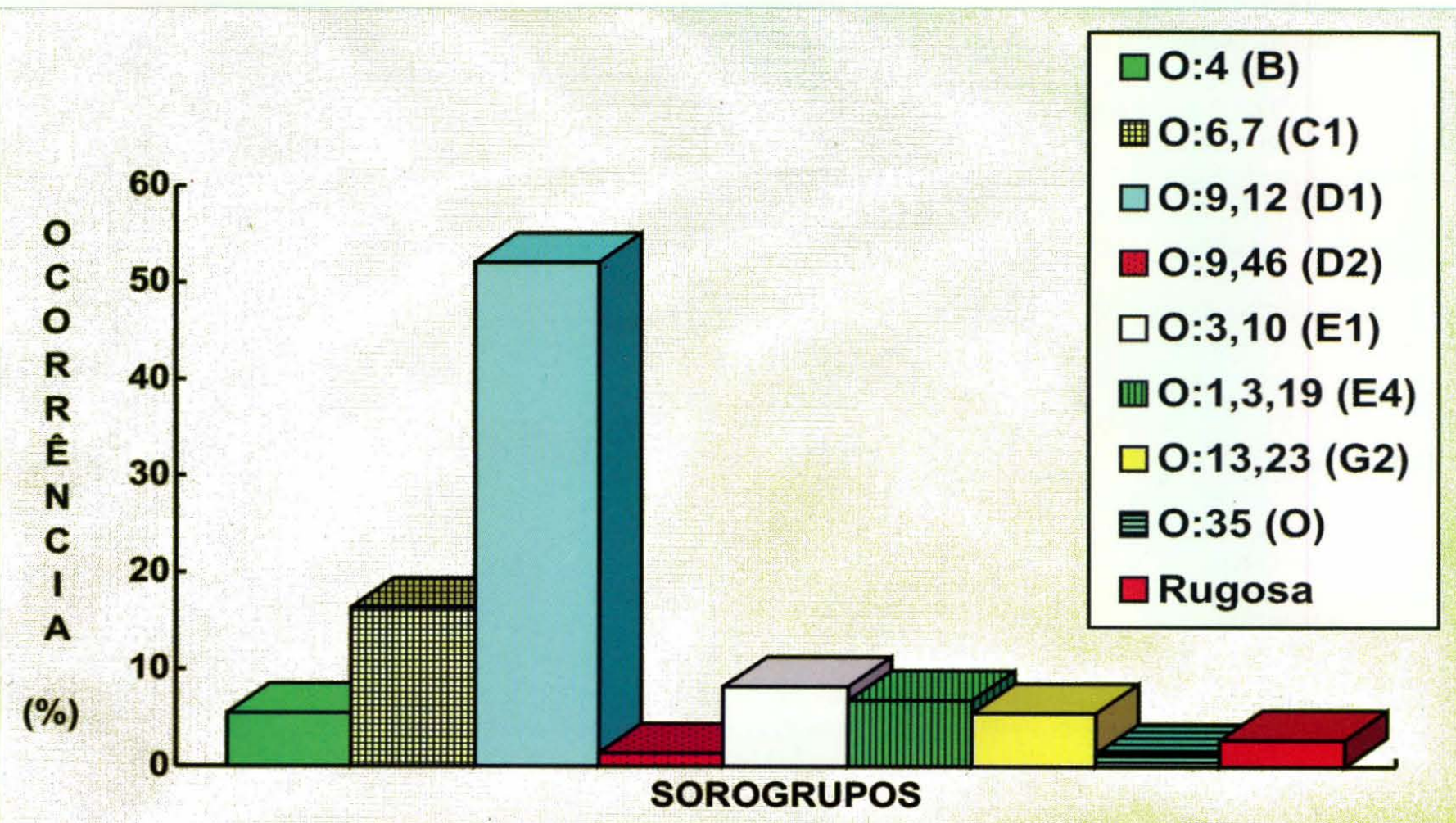

Figura 11. Distribuição dos sorogrupos de Salmonella spp. isolados no Laboratório de Ornitopatologia da FMVZ - UNESP, no período de 1994 a 1999. 


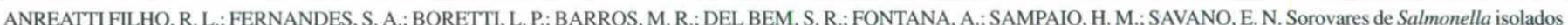

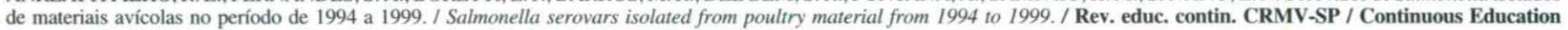
Journal CRMV-SP, São Paulo, volume 4, fascículo 3, p. 90 - 101, 2001.

de São Paulo Ter sido o responsável por $79,41 \%$ do isolamento de $S$. enteritidis, evidência esta de grande importância epidemiológica.

O sorogrupo O:9,12 com 52,02\% dos isolamentos de Salmonella deteve este índice com apenas quatro sorovares distintos, porque dentre esses estava inserido o enteritidis, responsável por 46,57\% dos isolamentos. Sequencialmente, mesmo com seis sorovares diferentes, o sorogrupo O:6,7 apresentou $16,38 \%$ dos isolamentos, enquanto todos os demais sorogrupos não superaram $8,2 \%$, individualmente.

De maneira geral, demonstramos a importância do rastreamento epidemiológico da Salmonella em relação à indústria avícola. O desenvolvimento extraordinário que vem sendo imposto pela avicultura mundial nas últimas décadas e a importante posição que as aves ocupam na cadeia alimentar, podendo compor o ciclo de propagação da Salmonella, tornam relevantes tanto os estudos epidemiológicos envolvendo todo o setor de produção avícola como o aspecto de saúde pública.

\section{Conclusões}

- O Laboratório de Ornitopatologia da FMVZ - UNESP, durante o período de 1994 a 1999, isolou com maior frequiência a $S$. enteritidis, proveniente de frangos de corte, poedeiras e matrizes pesadas.

- Frangos de corte e farinha de carne foram os responsáveis pelas maiores quantidades de sorovares de $\mathrm{Sal}$ monella isolados.

- S. pullorum, embora não freqüente, ainda está presente nos plantéis avícolas, especialmente nas aves de postura.

\section{SUMMARY}

Salmonella serovars isolated from poultry material from different geographical areas were identified in the 1994-1999 period. A total of 73 serovars was isolated, with recognition of 21 different serovars distributed in nine serogroups. Enteritidis was the serovar with highest incidence, $46.57 \%$, and was isolated from feed, litter and meat, poultry byproducts and fish meal. Natum had the second highest incidence, $6.84 \%$, and $80 \%$ of isolations were made from meat meal. S. pullorum represented $2.73 \%$ of the isolations, $100 \%$ from brown layers, confirming their susceptibility to infection by this serovar. Of the materials included in the present study, broilers and meat meal had more Salmonella spp., $41.09 \%$ and $30.13 \%$, respectively. Among the serovars isolated from broilers, $83.34 \%$ were enteritidis, but this serovar was not isolated from meat meal. The geographical area with the highest isolation of Salmonella spp. was the state of São Paulo with $82.19 \%$, followed by the state of Maranhão with $8.21 \%$. The state of São Paulo was responsible for $79.41 \%$ of S. enteritidis isolation. As the Enteritidis serovar belongs to the serogroup O:9,12, most isolations belonged to this serogroup, but it was the serogroup 0:6,7 that had the highest variation. Due to the role of poultry in the spreading cycle of this bacteria, the importance of epidemiological tracking of Salmonella in the poultry industry was shown, involving not only the health status of birds but also public health aspects.

Key words: Salmonella, poultry, serovars, serogroups, isolation.

\section{REFERÊNCIAS}

1. ASHKENAZI, S.; CLEARY, T. G.; MURRAY, B. E.; WANGER, A.; PICKENING, L. K. Quantitative analysis and partial characterization of cytotoxin production by Salmonella strains. Infection Immunity, v. 56, n. 12, p. 3089-3094, 1988.

2. ASLANZADEH, J.; PAULISSEN, L. J. Role of type 1 and type 3 fimbriae on the adherence and pathogenesis of Salmonella enteritidis in mice. Microbiology Immunology, v. 36, n. 4, p. 351-359, 1992.

3. ÁVILA, F. A.; SILVA, E. N.; FERREIRA; M. D. Isolamento e identificação de Salmonella em cama de aviário nos arredores de Belo Horizonte. Arquivo Escola Veterinária, v. 24, n. 3, p. 227-229, 1972
4. BARROW, P. A.; LOVELL, M. A. Experimental infection of egg-laying hens with Salmonella enteritidis phage type 4. Avian Pathology, v. 20, n. 2, 335-348, 1991.

5. BARROW, P. A. Salmonella control - past, present and future. Avian Pathology, v. 22, n. 4, p. 651-669, 1993.

6. BERCHIERI JÚNIOR, A.; IRINO, K.; NEME, S. N.; PAULILLO, A. C.; CALZADA, C. T.; FERREIRA, S. A.; PESSÔA, G. V. A. Contaminação por Salmonella em farinhas de origem animal utilizadas no preparo de ração. Pesquisa Veterinária Brasileira, v. 4, n. 3, p. 83-88, 1984.

7. BERCHIERI JÚNIOR, A.; ADACHI, S. Y.; CALZADA, C. T.; PAULILLO, A. C.; SCHOKEN-ITURRINO, R. P.; TAVECHIO, 


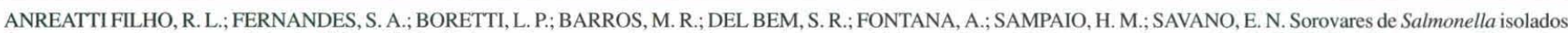

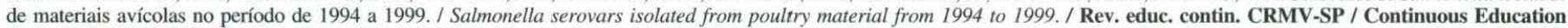
Journal CRMV-SP, São Paulo, volume 4, fascículo 3, p. 90 - 101, 2001.

A. T. Farinha de carne como fonte de Salmonella em granja avícola. Pesquisa Veterinária Brasileira, v. 9, n. 1/2, p. 9-12, 1989.

8. BERCHIERI JÚNIOR, A.; FERNANDES, S. A.; IRINO, K.; QUINTANA, J. L.; SANTOS, A. J. Salmonella in poultry feeds in Brazil. Revista Microbiologia, v. 24, n. 1, p. 22-25, 1993.

9. CRAVEN, S. E. Altered colonizing ability for the ceca of broiler chicks by lipopolysaccharide-deficient mutants of Salmonella typhimurium. Avian Diseases, v. 38, n. 3, p. 401-408, 1994.

10. DAVIES, R. H.; WRAY, C. Contribution of the lesser mealworm beetle (Alphitobius diaperinus) to carriage of Salmonella enteritidis in poultry. Veterinary Record, v. 137, n. 16, p. 407-408, 1995.

11. DUGUID, J. P.; CLEGG, S.; WILSON, M. I. The fimbrial and non-fimbrial hemagglutination of Escherichia coli. Journal Medical Microbiology, v. 12, n. 2, p. 213-227, 1979.

12. EBEL, E. D.; MASON, J.; THOMAS, L. A.; FERRIS, K. E; BECKMAN, M. G.; CUMMINS, D. R.; SCROEDER-TUCKER, L.; SUTHERLIN, W. D.; GLASSHOFF, R. L.; SMITHHISLER, N. M. Occurrence of Salmonella enteritidis in unpasteurized liquid egg in the United States. Avian Diseases, v. 37, n. 1, p. 135-142, 1993.

13. FALCÃO, D. P.; VALENTINI, S. R.; LEITE, C. Q. F. Pathogenic or potentially pathogenic bacteria as contaminants of fresh water from different sources in Araraquara, Brazil. Water Research, v. 27, n. 12, p. 1737-1741, 1993.

14. FERNANDES, S. A.; TAVECHIO, A. T.; NEVES, B. C.; IRINO, K.; ARAÚJO, E.; PERESI, J. T. M.; PACHECO, M. R.; CASTANHEIRA, I. A. Z. Salmonella enteritidis: atual sorotipo no Estado de São Paulo e susceptibilidade aos agentes antimicrobianos. In: CONGRESSO BRASILEIRO DE MICROBIOLOGIA, 18., 1995, Santos, SP. Anais... Santos, SP: Sociedade Brasileira de Microbiologia, 1995, p. 103.

15. GAST, R. K. Understanding Salmonella enteritidis in laying chickens: the contributions of experimental infections. International Journal Food Microbiology, v. 21, n. 1-2, p. 107-116, 1994.

16. GAST, R. K. Paratyphoid Infections. In: CALNEK, B. W. et al. (Eds.). Diseases of Poultry. 10. ed. Ames: State University Press, 1997. p. 97-121.

17. HACKING, W. C.; MITCHELL, W. R.; CARLSON, H. C. Sources of Salmonellae in broiler chickens in Ontario. Canadian Journal Comp. Medicine, v. 42, n. 4, p. 392-399, 1978.

18. HENZLER, D. J.; OPITZ, H. M. The role of mice in the epizootiology of Salmonella enteritidis infection on chicken layer farms. Avian Diseases, v. 36, n. 3, p. 625-631, 1992.

19. HENZLER, D. J.; EBEL, E.; SANDERS, J.; KRADEL, D.; MASON, J. Salmonella enteritidis in eggs from commercial chicken layer flocks implicated in human outbreaks. Avian Diseases, v. 38, n. 1, p. 37-43, 1994.

20. HIRD, D. W.; KINDE, H.; CASE, J. T.; CHARLTON, B. R.; CHIN, R. P.; WALKER, R. L. Serotypes of Salmonella isolated from California turkey flocks and their environment in 1984-89 and comparison with human isolates. Avian Diseases, v. 37, n. 3, p. 715-719, 1993.

21. HOFER, E.; SILVA FILHO, S. J.; REIS, E. M. F. Prevalência de sorovares de Salmonella isolados de aves no Brasil. Pesquisa Veterinária Brasileira, v. 17, n. 2, p. 55-62, 1997.

22. HUMPHREY, T. J. Public health implications of the infection of egg-laying hens with Salmonella enteritidis phage type 4. World's Poultry Science Journal, v. 46, n. 1, p. 5-13, 1990.

23. HUMPHREY, T. J.; WHITEHEAD, A.; GAWLER, A. H. L.; HENLEY, A.; ROWE, B. Numbers of Salmonella enteritidis in the contents of naturally contaminated hen eggs. Epidemiology and Infection, v. 106, n. 3, p. 489-496, 1991.
24. JIWA, S. F. H. Probing for enterotoxigenicity among the Salmonellae: an evaluation of biological assays. Journal Clinical Microbiology, v. 14, n. 5, p. 463-472, 1981.

25. JONES, F. T.; RIVES, D. V.; CAREY, J. B. Salmonella contamination in commercial eggs and an egg production facility. Poultry Science, v. 74, n. 4, p. 753-757, 1995.

26. KINDE, H.; ADELSON, M.; ARDANS, A.; LITTLE, E. H.; WILLOUGHBY, D.; BERCHTOLD, D.; READ, D. H.; BREITMEYER, R.; KERR, D.; TARBELL, R.; HUGHES, E. Prevalence of Salmonella in municipal sewage treatment plant effluents in Southern California. Avian Diseases, v. 41, n. 2, p. 392-398, 1997.

27. KOPANIC JUNIOR, R. J.; SHELDON, B. W.; WRIGHT, C. G. Cockroaches as vectors of Salmonella: laboratory and field trials. Journal Food Protection, v. 57, n. 2, p. 125-132, 1994.

28. KVENBERG, J. E.; ARCHER, S. L. Economic impact of colonization control on foodborne disease. Food Technology, v. 41, n. 7, p. 77-88, 1987.

29. LEE, A. Neglected niches. The microbial ecology of the gastrointestinal tract. Advances Microbial in Ecology, v. 8, p. 115$162,1985$.

30. LE MINOR, L.; POPOFF, M. Y. Designation of Salmonella enterica sp. nov., nom. rev., as the type and only species of the genus Salmonella. International Journal Systematic Bacteriology, v. 37, n. 4, p. 465-468, 1987.

31. LÍRIO, V. S.; ASTONE, S.; PIMENTEL, E. P.; CAMARGO, D.; STEFONI, S.; MIYAZAWA, T.C. Sorotipos de Salmonella isolados em alimentos. In: CONGRESSO BRASILEIRO DE MICROBIOLOGIA, 18., 1995, Santos, SP. Anais... Santos, SP: Sociedade Brasileira de Microbiologia, 1995, p. 32.

32. MALLINSON, E. T.; SNOEYENBOS, G. H. Salmonellosis. In: PURCHASE, H. G. et al., (Eds) a laboratory manual for the isolation and identification of avian pathogens. 3. ed., Pensilvania: American Association Of Avian Pathologistis. University of Pensilvania, 1989. p. 3-11.

33. McGARR, C.; MITCHELL, W. R.; CARLSON, H. C.; FISH, N. A. An epidemiological study of Salmonellae in broiler chicken production. Canadian Journal Public Health, v. 71, n. 1, p. 47-57, 1980.

34. POPPE, C.; GYLES, C. L. Relation of plasmids to virulence and other properties of Salmonellae from avian sources. Avian Diseases, v. 31, n. 4, p. 844-854, 1987.

35. RAMPLING, A.; UPSON, R.; WARD, L.; ANDERSON, J.; PETERS, E.; ROWE, B. Salmonella enteritidis PT4 infection of broiler chickens: a hazard to public health. Lancet, v. 2, n. 8660, p. 436438, 1989.

36. REITMEYER, J. C.; PETERSON, J. W.; WILSON, K. J. Salmonella cytotoxin a component of the bacterial outer membrane. Microbial Pathogeny, v. 1, n. 5, p. 503-510, 1986.

37. SOCKETT, P. N. The economic implication of human Salmonella infection. Journal Applied Bacteriology, v. 71, p. 289-295, 1991.

38. St. LOUIS, M. E.; MORSE, D. L.; POTTER, M. E.; DeMELFI, T. M.; GUZEWICH, J. J.; TAUXE, R. V.; BLAKE, P. A. The emergence of grade A eggs as a major source of Salmonella enteritidis infections. Journal American Medical Association, v. 259, n. 14, p. 2103-2107, 1988.

39. TAUNAY, A. E.; FERNANDES, S. A.; TAVECHIO, A. T.; NEVES, B. C.; DIAS, A. M. G.; IRINO, K. O laboratório de saúde pública e o problema da salmonelose no Estado de São Paulo. In: CONGRESSO BRASILEIRO DE MICROBIOLOGIA, 18., 1995, Santos, SP. Anais... Santos, SP: Sociedade Brasileira de Microbiologia, 1995. p. 103.

40. VELDMAN, A.; VAHL, H. A.; BORGGREVE, G. J.; FULLER, D.C. A survey of the incidence of Salmonella species and Enterobacteriaceae in poultry feeds and feed components. Veterinary Record, v. 136, n. 7, p. 169-172, 1995. 